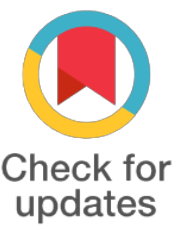

${ }^{*}$ For correspondence:

pvphuc@hcmus.edu.vn

Competing interests: The authors declare that no competing interests exist.

Received: 2017-04-30

Accepted: 2017-05-16

Published: 2017-09-05

Copyright The Author(s) 2017. This article is published with open access by BioMedPress (BMP).

This article is distributed under the terms of the Creative Commons Attribution License (CC-BY 4.0) which permits any use, distribution, and reproduction in any medium, provided the original author(s) and the source are credited.

\section{Production of endothelial progenitor cells from skin fibroblasts by direct reprogramming for clinical usages}

\author{
Phuc Van Pham, Ngoc Bich Vu, Thuy Thi-Thanh Dao, Ha Thi-Ngan Le, Lan Thi \\ Phi, Ngoc Kim Phan
}

Laboratory of Stem Cell Research and Application, University of Science, Vietnam National University HCMC, Ho Chi Minh city, Vietnam

\section{Abstract}

Endothelial progenitor cells (EPCs) play an important role in angiogenesis. However, they exist in limited numbers in the human body. This study was aimed to produce EPCs, for autologous transplantation, using direct reprogramming of skin fibroblasts under GMP-compliant conditions. Fibroblasts were collected and cultured from the skin in DMEM/F12 medium supplemented with $5 \%$ activated platelet-rich plasma and $1 \%$ antibiotic-antimycotic solution. They were then transfected with mRNA ETV 2 and incubated in culture medium under hypoxia ( $5 \%$ oxygen) for $14 \mathrm{~d}$. Phenotype analysis of transfected cells confirmed that single-factor ETV 2 transfection successfully reprogrammed dermal fibroblasts into functional EPCs. Our results showed that ETV 2 mRNA combined with hypoxia can give rise to functional EPCs. The cells exhibited functional phenotypes similar to endothelial cells derived from umbilical cord vein; they expressed CD31 and VEGFR2, and formed capillary-like structures in vitro. Moreover, these EPCs could significantly improve hindlimb ischemia in mouse models. Although the direct conversion efficacy was low $(3.12 \pm 0.98 \%)$, altogether our study demonstrates that functional EPCs can be produced from fibroblasts and can be used in clinical applications.

\section{Keywords}

Endothelial progenitor cells Direct conversion ETV2 Hindlimb ischemia Ischemia Stem cell therapy Epigenetic reprogramming

Funding

References 